\title{
Clinicopathological and Prognostic Significance of Cancer Stem Cell Markers in Ovarian Cancer Patients: Evidence from 52 Studies
}

\author{
Yifeng Tao ${ }^{a}$ Hui Lia Rongyong Huang ${ }^{c}$ Dan Mo ${ }^{b}$ Tian Zeng ${ }^{b}$ Min Fang ${ }^{a}$ \\ Meiqin $\mathrm{Li}^{\mathrm{a}}$
}

\begin{abstract}
aDepartment of Clinical Laboratory, The Afffiliated Tumor Hospital of Guangxi Medical University, Nanning, Guangxi, bDepartment of Surgery, Maternal and Child Health Hospital of The Guangxi Zhuang Autonomous Region, Nanning, Guangxi, ‘School of Marine Sciences, Guangxi University, Nanning, Guangxi, China
\end{abstract}

\section{Key Words}

Aldh1 • CD117 • CD133 • CD44 • Ovarian cancer • Meta-analysis

\begin{abstract}
Background/Aims: Relevant markers of cancer stem cells (CSCs) may serve as commonly used biomarkers of ovarian cancer (OC). However, their actual clinicopathological and prognostic significance remains inconclusive. Thus, we conducted a meta-analysis to quantitatively evaluate the association between the expression of CSC-relevant markers (ALDH1, CD117, CD133, and CD44) and OC. Methods: We used an odds ratio (OR) and a hazard ratio (HR) with a 95\% confidence interval (CI) to estimate the effects by analyzing 52 studies from a literature search. Heterogeneity and sensitivity were evaluated, as well. Publication bias was assessed using funnel plots and Egger tests. Results: ALDH1 expression was statistically associated with FIGO stage $(\mathrm{OR}=1.872,95 \% \mathrm{CI}=1.14-3.076, \mathrm{P}=0.013)$ and lymph invasion $(\mathrm{OR}=2.78,95 \% \mathrm{CI}=1.08$ 7.152, $P=0.034)$. CD117 expression was significantly associated with FIGO stage $(O R=2.01$, $95 \% \mathrm{CI}=1.35-2.98, \mathrm{P}=0.001)$. CD133 expression was correlated with $\mathrm{FIGO}$ stage $(\mathrm{OR}=3.410$, $95 \% \mathrm{CI}=2.196-5.294, \mathrm{P}<0.001)$ and differentiation grade $(\mathrm{OR}=2.672,95 \% \mathrm{CI}=1.354-5.272$, $P=0.005) . C D 44 s$ was related to chemotherapy resistance $(O R=3.218,95 \% C I=1.148-9.016$, $\mathrm{P}=0.026)$. Furthermore, overexpression of $\mathrm{ALDH1}(\mathrm{HR}=1.494,95 \% \mathrm{CI}=1.207-1.849, \mathrm{P}<0.001)$, CD117 (HR=1.395, 95\%CI=1.025-1.898, $\mathrm{P}=0.034)$ or $\mathrm{CD} 44 \mathrm{~s}(\mathrm{HR}=1.725,95 \% \mathrm{CI}=1.135-2.623$, $\mathrm{P}=0.011$ ) was associated with poor OS. Further, overexpression of both ALDH1 (HR=1.524, 95\% CI $=1.158-2.007, P=0.003)$ and $C D 44 s \quad(H R=2.12,95 \% C I=1.692-2.657, P<0.001)$ was correlated with worse DFS. Conclusion: CSC markers are useful predictive or prognostic biomarkers for OC in clinical assessments. Combined detection of CSC marker expression may be a powerful tool for prognostic predictions in clinical practice for patients with OC.

Y. Tao, H. Li and R. Huang contributed equally to this work.




\section{Introduction}

Ovarian cancer (OC) is the fifth leading cause of cancer deaths in women and the most lethal gynecological malignancy [1]. Although most OC patients initially exhibit a sensitive response to platinum-based chemotherapy, the overall survival (OS) of patients with OC is relatively low because $70 \%$ of patients are diagnosed with an advanced stage of OC and will ultimately succumb to chemo-resistant disease [2-4]. More seriously, the five-year survival rate of OS remains poor [2]. Therefore, there is a great need for identification of molecular biological prognostic markers to predict patient outcomes, which could also be beneficial in developing strategies and improving survival rates for OC.

Cancer stem cells (CSCs) are a distinct subpopulation of cancer cells characterized by their ability to generate heterogeneity and sustain tumor self-renewal [5-7]. Recently, accumulated evidence has identified CSCs as a pivotal players in OC progression and prognosis [8-10]. Several stem cell markers have been described for OC, including CD44, CD133, ALDH1, CD117, CD24, BMP and EpCAM [11-16]. Furthermore, it has been reported that CSC markers, such as ALDH1, CD117, CD133 and CD44, may serve as valuable prognostic indicators for OC [17-20]. However, due to the diversity of research methods employed, differences in cut-off value, study sample size, and variance in race, the prognostic value of ALDH1, CD117, CD133 and CD44 expression in OC remains controversial [18, 21-27].

No study has compared the relationship between these 4 common CSC markers and OC, including clinicopathological features of the disease, and the effect of the markers on survival. Therefore, we collected the available literature and conducted this meta-analysis to determine whether ALDH1, CD117, CD133 or CD44 overexpression would correlate with OC clinicopathology and prognosis and to explain which of these markers would have more clinical value based on meta-analysis evidence.

\section{Materials and Methods}

\section{Literature search strategy}

Literature searches without any linguistic limitations were conducted up to May 3, 2017, in the following electronic databases: PubMed and Web of Science. The search strategy included the following words and phrases: ("Aldehyde Dehydrogenase" or "ALDH”) and ("Ovarian Neoplasm," “Ovarian Carcinoma," "Ovarian Cancer," and "Ovarian Tumor"); (“CD117," "c-kit" or "tyrosine-protein kinase Kit") and ("Ovarian Neoplasm," “Ovarian Carcinoma," “Ovarian Cancer," and "Ovarian Tumor”); (“CD133," "Prom-1" or "AC133”) and ("Ovarian Neoplasm,"“Ovarian Carcinoma," "Ovarian Cancer," and "Ovarian Tumor"); and ("CD44") and ("Ovarian Neoplasm," "Ovarian Carcinoma," "Ovarian Cancer" and "Ovarian Tumor"). Additionally, the reference lists of relevant articles were screened to identify additional relevant studies.

\section{Study selection}

Two reviewers (Yifeng Tao and Meiqin Li) selected the eligible studies independently, and disagreements were resolved by discussion. The eligible studies for this meta-analysis had to meet the following inclusion criteria: 1) the expression of OC CSC-relevant markers (ALDH1, CD117, CD133 and CD44) was detected in cancer tissue rather than in the serum or any other kinds of specimens; 2) the expression of these markers was detected using an immunohistochemistry (IHC) method; 3) the relationship between the expression of these markers and clinicopathological characteristics of OC was evaluated; 4) the expression of these markers with OS/disease-free survival (DFS) for OC was reported; and 5) HRs and 95\% CIs were provided in the text, or sufficient data was provided for the calculation of HRs and 95\% Cis. Non-research articles, studies that were focused on animal or human cell lines, or papers lacking information on OC prognosis were excluded.

In addition, due to a lack of adequate information for CD44v3, CD44v7-8, CD44v9, and CD44v10, we analyzed only two CD44 isoforms, namely, CD44s and CD44v6. 


\section{Cellular Physiology Cell Physiol Biochem 2018;46:1716-1726 \\ \begin{tabular}{ll|l} 
and Biochemistry Published online: May 04, 2018 & $\begin{array}{l}\text { (c) } 2018 \text { The Author(s). Published by S. Karger AG, Basel } \\
\text { www.karger.com/cpb }\end{array}$
\end{tabular} \\ Tao et al.: Ovarian Cancer Stem Cell Markers}

\section{Data extraction}

Two investigators (Rongyong Huang and Meiqin Li) carried out the data extraction independently, and disagreements were resolved by a 3rd party (Yifeng Tao). The following information was extracted: first author's surname, year of publication, country of origin, sample size, cut-off values forALDH1/CD117/ CD133/CD44, FIGO stage, and survival data.

\section{Qualitative assessment}

The quality of each of the eligible studies was assessed independently by 2 investigators using the Newcastle-Ottawa Quality Assessment Scale (NOS) for cohort studies. Briefly, the scale uses a star system to indicate the quality of each study. Studies that receive a score of $\geq 7$ stars are considered to be of high quality.

\section{Statistical Analysis}

The odds ratio (OR) and 95\% confidence interval (CI) were used to assess the correlation between the expression of these OC CSC markers and clinicopathological parameters, including FIGO stage (III/IV versus I/II), tumor differentiation grade (poor versus well/moderate), lymph nodal metastasis (positive versus negative), pathological type (serous type versus other type) and response to chemotherapy (resistant versus sensitive). In the present study, an $\mathrm{OR}>1$ indicated a higher probability of tumor progression in OC patients overexpressing these CSC markers. Hazard ratios (HR) were used as a summary statistic for survival outcomes, as described by Parmar et al. An HR greater than 1 represented poor prognosis in OC. Heterogeneity among primary studies was assessed with the Q-test and the $\mathrm{I}^{2}$ statistic. A Q test $\mathrm{P}$ value $<0.10$ and/or an $\mathrm{I}^{2}$ statistic $>50 \%$ indicated significant heterogeneity between studies, and we used the random effects model to calculate the pooled OR/HR and 95\% CI [28]. Otherwise, the fixed effects model was used [29]. Begg's funnel plots were used to evaluate publication bias. Sensitivity analysis was introduced to evaluate the influence of a single study on the overall estimate. All statistical analyses were performed using Stata 12.0 statistical software (Stata Corporation, College Station, TX, USA). A two-tailed P $<0.05$ was considered to be statistically significant.

\section{Results}

\section{Study characteristics}

The literature selection process for choosing eligible studies is shown in Fig. 1. In accordance with the inclusion criteria, a total of 52 articles were eligible for the metaanalysis [13, 17-27, 30-69]. The basic characteristics of each eligible study are summarized in Table 1. The eligible studies were published between 1997 and 2017. The sample sizes of the included studies ranged from 11 to 440 . Among these studies, 15 studies involved patients with ALDH1 $[19,22,26$, 30-41], 8 studies involved patients with CD133 [18, 23, 25, 30, 31, 37, 42, 43], 25 studies involved patients

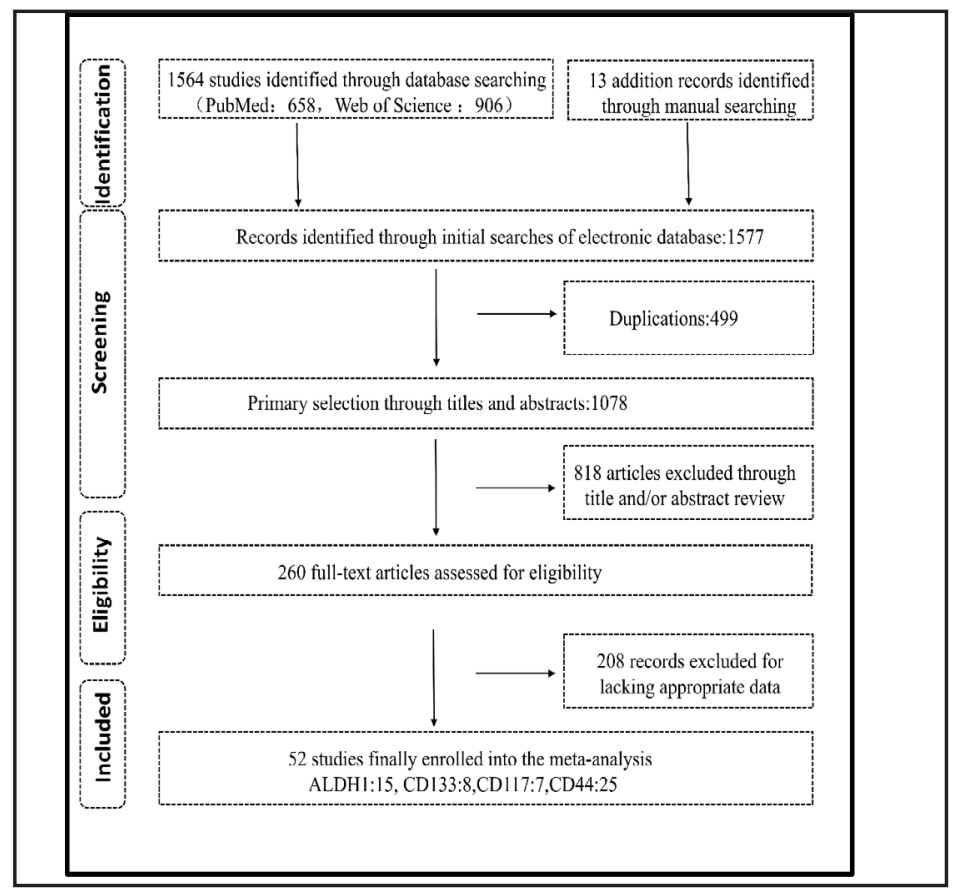

Fig. 1. The flowchart of the study selection process. 
with CD44 [17, 21, 24, 4464, 66], 7 studies involved patients with CD117 [13, 20, 26, 27, 67-69], 3 studies involved patients with ALDH1 and CD133 [30, 31, 37], and 1 study involved patients with ALDH1 and CD117 [26]. According to the NOS quality assessment, 52 of the studies were categorized as high quality.

Correlation of ALDH1/ CD117/CD133/CD44 with clinicopathological features of OC patients

Table 2 shows the results for correlation between ALDH1/CD117/ CD133/CD44 and the clin ic op a tholog i cal parameters. Overall analyses demonstrated that ALDH1 expression was statistically associated with FIGO stage (OR=1.872, $95 \% \mathrm{C} \mathrm{I}=1.14-3.076$, $\mathrm{P}=0.013)$ and lymph invasion $\quad(\mathrm{OR}=2.78$, $95 \% \mathrm{C} \mathrm{I}=1.08-7.152$, $\mathrm{P}=0.034$ ) (Fig. 2A-B). CD117 expression was significantly associated with FIGO stage $(\mathrm{OR}=2.01, \quad 95 \% \mathrm{CI}=1.35-$ 2.98, $\mathrm{P}=0.001$ ) (Fig. 2E). CD133 expression was correlated with FIGO stage $(\mathrm{OR}=3.41, \quad 95 \% \mathrm{CI}=2.196$ 5.294, $\quad \mathrm{P}<0.001)$, which was consistent with the results for ALDH1 (Fig. 2C). Moreover, CD133 expression was statistically associated with differentiation grade $(\mathrm{OR}=2.672, \quad 95 \% \mathrm{CI}=1.354$ -

5.272, $\mathrm{P}=0.005$ ) (Fig. 2D), suggesting that $\mathrm{CD} 133$ might be involved in the malignant progression of OC. It is worth noting that overexpression of CD44s is associated with chemotherapy resistance $(\mathrm{OR}=3.218,95 \% \mathrm{CI}=1.148-9.016, \mathrm{P}=0.026)$ (Fig. 2F), indicating that high CD 44s expression possibly contributes to a high risk of chemotherapy resistance in OC patients. However, no clear correlation was found between CD44s/CD44v6 expression and FIGO stage, lymph invasion, differentiation grade, and pathological type (all $\mathrm{P}>0.05$ ).

Table 1. Association between CSCs expression and ovarian cancer prognosis. Abbreviations: OS, overall survival; DFS, disease-free survival; Pbias, the p-value of Egger linear regression test for evaluating publication bias

\begin{tabular}{|c|c|c|c|c|c|c|}
\hline Reference & Year & Country & Case & Cutoff value & FIGO stage & Outcome \\
\hline \multicolumn{7}{|l|}{ ALDH1 } \\
\hline Yu[6] & 2017 & China & 207 & Scores $\geq 3$ & I -IV & os \\
\hline Ruscito[31] & 2017 & Germany & 112 & Scores $\geq 2$ & I -IV & OS,DFS \\
\hline Jing[30] & 2016 & China & 62 & Scores $\geq 4$ & I -IV & NA \\
\hline Huang[32] & 2015 & China & 248 & Scores $\geq 1$ & I - IV & OS,DFS \\
\hline Sun[33] & 2015 & China & 100 & Scores $\geq 9$ & I -IV & DFS \\
\hline Ayub[26] & 2015 & Germany & 55 & NA & III-IV & OS,DFS \\
\hline Chen[34] & 2015 & China & 80 & $\geq 10 \%$ & I -IV & os \\
\hline Kuroda[36] & 2013 & Japan & 99 & $>$ mean ratio & I - IV & OS,DFS \\
\hline Liebscher[35] & 2013 & Germany & 131 & Scores $\geq 4$ & I -IV & os \\
\hline Ricci[37] & 2013 & Italy & 47 & NA & I -IV & OS,DFS \\
\hline Wang[38] & 2012 & China & 84 & $>50 \%$ & I -IV & OS,DFS \\
\hline Rahadiani[39] & 2011 & Japan & 98 & $>10 \%$ & NA & OS,DFS \\
\hline Deng[40] & 2010 & USA & 439 & $\geq 10 \%$ & NA & OS,DFS \\
\hline Landen[41] & 2010 & USA & 65 & $>1 \%$ & III-IV & OS,DFS \\
\hline Chang[22] & 2009 & USA & 440 & Scores $\geq 2$ & I -IV & OS,DFS \\
\hline \multicolumn{7}{|l|}{ CD117 } \\
\hline Conic[67] & 2015 & Serbia & 240 & $>25 \%$ & I -IV & os \\
\hline Ayub[26] & 2015 & Germany & 55 & NA & III-IV & OS,DFS \\
\hline Huang[13] & 2014 & Norway & 242 & $>10 \%$ & I -IV & OS,DFS \\
\hline Brustmann[20] & 2005 & Austria & 41 & NA & I -III & OS \\
\hline Khalifeh[69] & 2005 & USA & 118 & NA & III-IV & os \\
\hline Lassus[68] & 2004 & Finland & 516 & NA & I -IV & os \\
\hline Tonary[27] & 2000 & Canada & 35 & NA & I -IV & OS,DFS \\
\hline \multicolumn{7}{|l|}{ CD133 } \\
\hline Ruscito[31] & 2017 & Germany & 112 & $>10 \%$ & I $-\mathrm{IV}$ & OS,DFS \\
\hline Jing[30] & 2016 & China & 64 & Scores $\geq 4$ & I $-\mathrm{IV}$ & NA \\
\hline Liang[25] & 2016 & China & 120 & Scores $>0$ & I -IV & OS \\
\hline $\operatorname{Kim}[42]$ & 2014 & Korea & 59 & Scores $\geq 1.5$ & I -IV & NA \\
\hline Francesca[37] & 2013 & Italy & 91 & Scores $>0$ & I -IV & OS,DFS \\
\hline Qin [43] & 2012 & China & 123 & $\geq 10 \%$ & III-IV & os \\
\hline Zhang[18] & 2012 & USA & 400 & Scores $>0$ & I -IV & OS,DFS \\
\hline Ferrandina[23] & 2009 & Italy & 160 & Scores $>0$ & III-IV & OS,DFS \\
\hline \multicolumn{7}{|l|}{ CD 44s } \\
\hline Elzarkaa[24] & 2016 & Egypt & 96 & Scores $\geq 3$ & III-IV & OS,DFS \\
\hline Bonneau[44] & 2015 & France & 32 & $>$ mean ratio & III-IV & OS,DFS \\
\hline Wang[45] & 2015 & China & 86 & Scores $\geq 5$ & I -IV & os \\
\hline Gao [46] & 2015 & USA & 26 & Scores $>0$ & I -IV & OS,DFS \\
\hline Zhu[47] & 2015 & USA & 92 & Scores $>100$ & I -IV & OS,DFS \\
\hline Jing[48] & 2013 & USA & 483 & $>0 \%$ & I -IV & OS,DFS \\
\hline $\mathrm{Hu}[50]$ & 2013 & China & 92 & Scores $\geq 3$ & I -IV & os \\
\hline Ryabtseva[51] & 2013 & Ukraine & 72 & $>10 \%$ & I -III & os \\
\hline Liu[52] & 2012 & USA & 33 & NA & I -IV & OS,DFS \\
\hline Steffensen[53] & 2011 & Denmark & 117 & $\geq 20 \%$ & I -IV & DFS \\
\hline Chen[54] & 2009 & China & 120 & $>25 \%$ & I -IV & NA \\
\hline Cho[17] & 2006 & Korea & 158 & $>10 \%$ & I -IV & NA \\
\hline Sari[49] & 2003 & Finland & 307 & $>10 \%$ & I -IV & OS,DFS \\
\hline Rodriguez[21] & 2003 & Canada & 121 & $>0 \%$ & I -IV & os \\
\hline $\operatorname{Ross}[55]$ & 2001 & USA & 64 & $>0 \%$ & I -IV & os \\
\hline Kayastha[56] & 1999 & USA & 56 & $>0 \%$ & NA & os \\
\hline \multicolumn{7}{|l|}{ CD44V6 } \\
\hline Motohara[61] & 2016 & Japan & 186 & $>10 \%$ & I -III & OS,DFS \\
\hline Tjhay [58] & 2015 & Japan & 59 & $>10 \%$ & III-IV & OS,DFS \\
\hline Wang[66] & 2014 & China & 102 & Scores $\geq 2$ & I -IV & OS,DFS \\
\hline Shi[57] & 2013 & China & 90 & Scores $\geq 2$ & I -III & NA \\
\hline Gun[60] & 2012 & Turkey & 47 & Scores $>0$ & I -IV & NA \\
\hline Zhou[62] & 2012 & China & 62 & $>5 \%$ & I -IV & os \\
\hline Hong[59] & 2006 & Korea & 25 & $\geq 10 \%$ & I -IV & NA \\
\hline Cho[17] & 2006 & Korea & 158 & $>10 \%$ & I -IV & NA \\
\hline Rodriguez[21] & 2003 & Canada & 121 & $>0 \%$ & I -IV & OS,DFS \\
\hline Darai[64] & 1998 & France & 36 & $>0 \%$ & I -III & NA \\
\hline Yorishima[63] & 1997 & Japan & 11 & $>0 \%$ & I -IV & NA \\
\hline
\end{tabular}


Impact of ALDH1/ CD117/CD133/CD44 expression on survival of OC patients

To further investigate the relationship between ALDH1/CD117/CD133/ CD44 and the prognosis of OC patients, survival analysis of the HR for OS and DFS was conducted. The results are shown in Fig. 3 and Table 3.

The data for this analysis indicated that overexpression of ALDH1 $(\mathrm{HR}=1.494,95 \% \mathrm{CI}=1.207-$ 1.849, $\mathrm{P}<0.001), \quad \mathrm{CD} 117$ $(\mathrm{HR}=1.395, \quad 95 \% \mathrm{CI}=1.025-$ $1.898, \mathrm{P}=0.034$ ) or $\mathrm{CD} 44 \mathrm{~s}$ (HR=1.725, 95\% $\mathrm{CI}=1.135$ 2.623, $\quad \mathrm{P}=0.011$ ) is associated with poor OS (Fig. 3A, C). Furthermore, overexpression of both ALDH1 (HR=1.524, $95 \% \mathrm{C} \mathrm{I}=1.158-2.007$, $\mathrm{P}=0.003)$ and $\mathrm{CD} 44 \mathrm{~s}$ (HR=2.12, 95\% $\mathrm{CI}=1.692$ 2.657, $\quad \mathrm{P}<0.001) \quad$ is correlated with worse DFS (Fig. 3B,D). However, data analysis showed that there is no significant relationship between the overexpression of CD117 or CD133 and DFS. Additionally, a relationship between CD44v6 overexpression and poor OS rate was not found, and there was lack of sufficient information to study the relationship between CD44v6 expression and DFS.

Sensitivity analysis and Publication Bias

Sensitivity analysis indicated that most studies did not substantially influence the pooled OR/ $H R$, except for the results related to OS and CD44v6
Table 2. Overall analysis of CSCs expression association with clinical features. Abbreviations: $\mathrm{P}_{\text {bias }}$, the p-value of Egger linear regression test for evaluating publication bias

\begin{tabular}{lccccc}
\hline & OR & $95 \%$ CI & P & $\mathrm{I}^{2}$ & Pbias \\
\hline ALDH1 & & & & & \\
FIGO stage(III/IV vs I / II) & 1.872 & $1.14-3.076$ & 0.013 & $62.10 \%$ & 0.581 \\
Differentiation(poor vs well/moderate) & 0.916 & $0.498-1.687$ & 0.779 & $72.80 \%$ & 0.278 \\
Lymph invasion (yes vs no) & 2.78 & $1.08-7.152$ & 0.034 & $79.40 \%$ & 0.573 \\
Pathological type(serous type vs other type) & 0.802 & $0.545-1.181$ & 0.265 & $0.41 \%$ & 0.409 \\
Response to chemotherapy(resistant vs sensitive) & 0.845 & $0.231-3.865$ & 0.937 & $84.80 \%$ & 0.306 \\
CD117 & & & & & \\
FIGO stage(III/IV vs I / II) & 2.01 & $1.35-2.98$ & 0.001 & $15.30 \%$ & 0.524 \\
Differentiation(poor vs well/moderate) & 1.698 & $0.819-3.519$ & 0.154 & $62.10 \%$ & 0.627 \\
Pathological type(serous type vs other type) & 3.166 & $1.777-5.642$ & $<0.001$ & $0.00 \%$ & 0.145 \\
CD133 & & & & & \\
FIGO stage(III/IV vs I / II) & 3.41 & $2.196-5.294$ & $<0.001$ & $48.40 \%$ & 0.405 \\
Differentiation(poor vs well/moderate) & 2.672 & $1.354-5.272$ & 0.005 & $50.30 \%$ & 0.404 \\
Pathological type(serous type vs other type) & 1.305 & $0.830-2.052$ & 0.248 & $0.00 \%$ & 0.051 \\
Response to chemotherapy(resistant vs sensitive) & 1.063 & $0.504-2.243$ & 0.872 & $75.00 \%$ & 0.938 \\
CD44s & & & & & \\
FIGO stage(III/IV vs I / II) & 1.055 & $0.424-2.62$ & 0.909 & $90.40 \%$ & 0.106 \\
Differentiation(poor vs well/moderate) & 1.609 & $0.561-4.615$ & 0.377 & $90.50 \%$ & 0.055 \\
Lymph invasion (yes vs no) & 1.241 & $0.762-2.022$ & 0.385 & $43.60 \%$ & 0.292 \\
Pathological type(serous type vs other type) & 0.668 & $0.401-1.113$ & 0.121 & $34.30 \%$ & 0.545 \\
Response to chemotherapy(resistant vs sensitive) & 3.218 & $1.148-9.016$ & 0.026 & $90.90 \%$ & 0.053 \\
CD44V6 & & & & & \\
FIGO stage(III/IV vs I / II) & 0.99 & $0.496-1.974$ & 0.976 & $55.40 \%$ & 0.269 \\
Differentiation(poor vs well/moderate) & 1.596 & $0.848-3.003$ & 0.148 & $48.90 \%$ & 0.415 \\
Lymph invasion (yes vs no) & 0.927 & $0.606-1.418$ & 0.725 & $17.30 \%$ & 0.266 \\
Pathological type(serous type vs other type) & 0.661 & $0.400-1.091$ & 0.105 & $44.90 \%$ & 0.236 \\
\hline
\end{tabular}

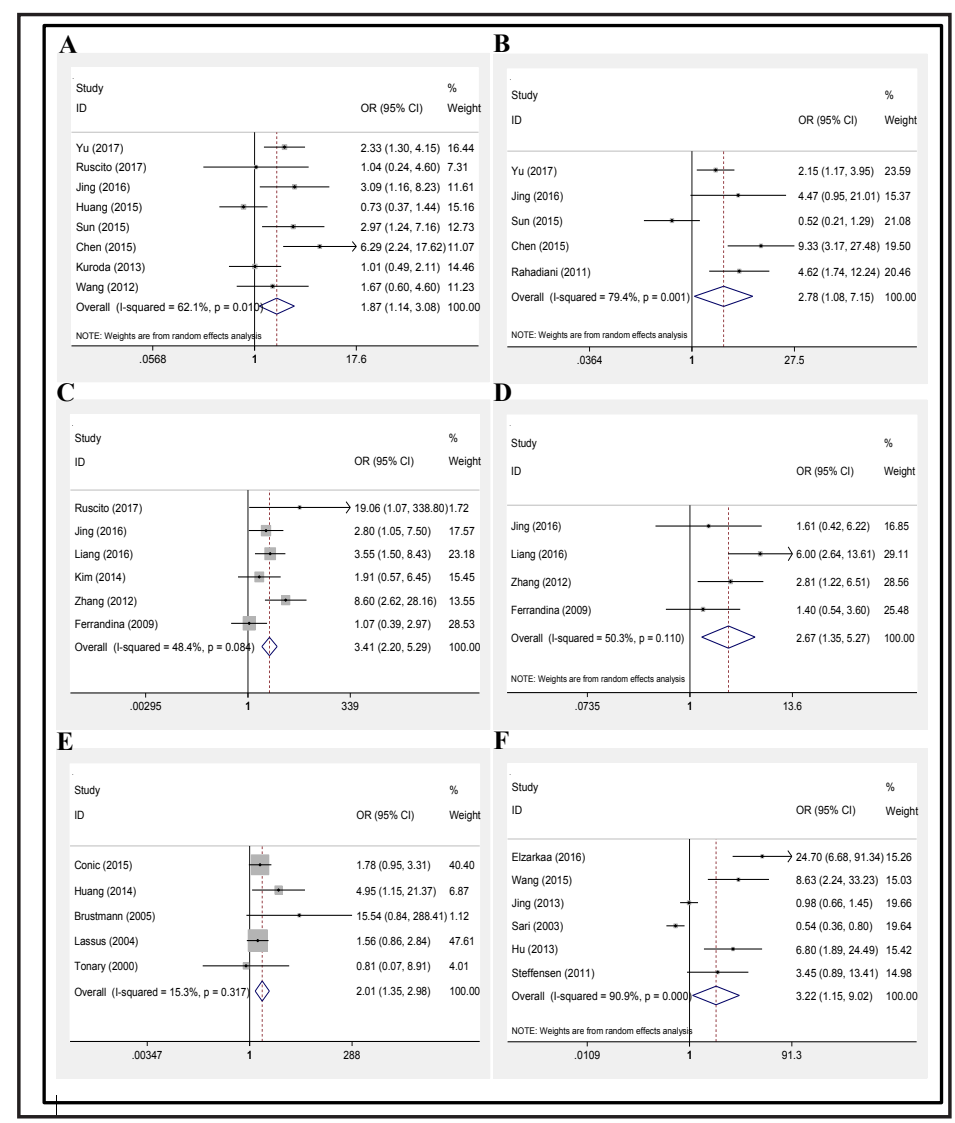

Fig. 2. Association of CSCs expression with clinical features.(A-B) association of ALDH1 expression with FIGO stage (A) and lymph invasion (B); (C-D) association of CD133 expression with FIGO stage (C) and differentiation grade (D); (E) association of CD117 expression with FIGO stage; (F) association of CD44s expression with chemotherapy resistant. 
expression. Publication bias analysis of the studies indicated there was no obvious publication bias in most studies, except for the results related to $\mathrm{OS}$ and ALDH1 expression, which suggests that a publication bias possibly existed for OS results (Table 2 ).

\section{Discussion}

Whereas advanced ovarian cancer is generally responsive to conventional combinations of primary cytoreductive surgery and paclitaxel-platinum chemotherapy initially, most ovarian cancer patients will inevitably relapse with metastasis, recurrence, and drug resistance [2, 3]. Although deadly, ovarian cancer is one of the more chemosensitive solid malignancies. One model by which to explore ovarian cancer tumor heterogeneity is the cancer stem cell hypothesis. This idea proposes that within a heterogeneous ovarian tumor, there are small cell populations with increased tumorigenicity and differentiating capacity compared to other tumor cells that are responsible for ovarian tumor initiation, recurrence, and metastasis $[70,71]$.

The clinical significance of the most frequently used CSC markers OC, ALDH1, CD117, CD133 and CD44 remains contradictory and inconclusive. Based on these controversial studies, a meta-analysis was conducted to
evaluate the precise impact of ALDH1, CD117, CD133 and CD44 on the clinicopathological features and prognosis of OC.

ALDH1 plays a role in retinoic acid formation by oxidizing the all-trans-retinal and 9-cisretinal involved in retinoid signaling, which has been linked to the stemness of CSCs [72,

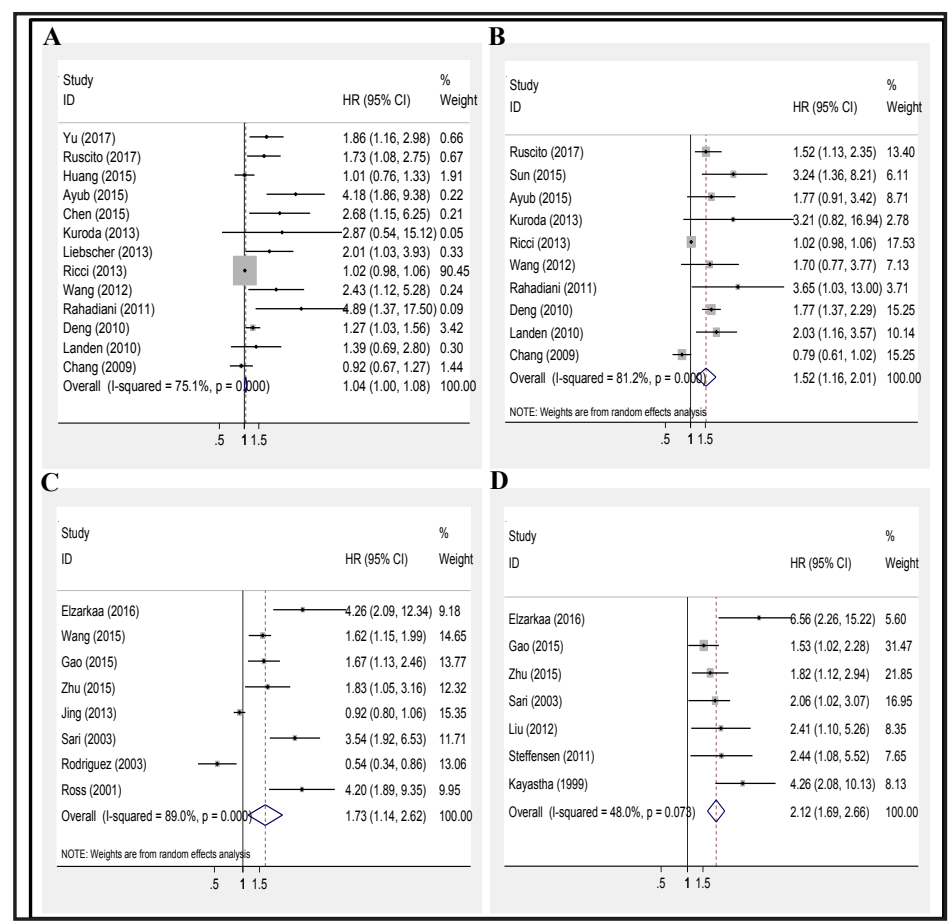

Fig. 3. Association between CSCs expression and ovarian cancer prognosis. (A-B) association of ALDH1 expression with overall survival (A) and disease-free survival (B); (C-D) association of CD44s expression with overall survival (C) and disease-free survival (D).

Table 3. Association between CSCs expression and ovarian cancer prognosis. Abbreviations: OS, overall survival; DFS, disease-free survival; Pbias, the p-value of Egger linear regression test for evaluating publication bias

\begin{tabular}{lccccc}
\hline & HR & $95 \%$ CI & P & $I^{2}$ & Pbias \\
\hline ALDH1 & & & & & \\
OS & 1.494 & $1.207-1.849$ & $<0.001$ & $75.10 \%$ & 0.001 \\
DFS & 1.524 & $1.158-2.007$ & 0.003 & $81.20 \%$ & 0.063 \\
CD117 & & & & & \\
OS & 1.395 & $1.025-1.898$ & 0.034 & $69.20 \%$ & 0.438 \\
DFS & 1.304 & $0.789-2.167$ & 0.298 & $70.48 \%$ & 0.674 \\
CD133 & & & & & \\
OS & 1.109 & $0.989-1.243$ & 0.076 & $73.60 \%$ & 0.122 \\
DFS & 1.542 & $0.863-2.756$ & 0.144 & $87.20 \%$ & 0.116 \\
CD44s & & & & & \\
OS & 1.725 & $1.135-2.623$ & 0.011 & $89.00 \%$ & 0.051 \\
DFS & 2.12 & $1.692-2.657$ & $<0.001$ & $48 \%$ & 0.066 \\
CD44v6 & & & & & \\
OS & 1.363 & $0.270-6.89$ & 0.708 & $90.60 \%$ & 0.416 \\
\hline
\end{tabular}


73]. Moreover, ALDH1 plays a key role in the maintenance of ovarian cancer stem cell-like properties and might mediate carboplatin resistance by altering regulation of the cell cycle and DNA repair networks [72].

CD117 (c-kit), a well-known proto-oncoprotein, is normally activated by binding to its ligand (stem cell factor), which activates cell-signaling cascades that are important in the regulation of cell proliferation, apoptosis, adhesion, and differentiation [74, 75].

CD133, a pentaspan membrane glycoprotein, has been identified as a CSC marker for various cancers. The biological function of CD133 remains unclear, but it may be involved in primitive cell differentiation and epithelial-mesenchymal interactions [76].

CD44 is a receptor for the extracellular matrix component hyaluronic acid and other extracellular matrix components that enable CSCs to sense environmental changes and mediate signal transduction to regulate CSC stemness properties [77]. CD44-hyaluronan complex activates Nanog, an embryonic stem cell transcription factor important in regulating CSC survival, self-renewal, maintenance, and chemoresistance [78].

Our results indicate that positive ALDH1, CD117, CD133 and CD44s expression can effectively predict several clinicopathological features and poor outcomes in patients with OC. Because the related features do not overlap, combined detection of ALDH1, CD117, CD133 and CD44s expression may be an especially effective tool for diagnosis of patients with OC. However, because publication bias was observed in the pooled HR for the OS and DFS of ALDH1 expression, our results should be cautiously interpreted.

Several potential limitations should be taken into consideration and additional results should also be interpreted cautiously. First, diverse antibody clones and antibody concentrations were used in detecting ALDH1, CD117, CD133 and CD44 expression, which could cause inconsistent results. Second, lack of a universal standard for defining high and low expression of CSC markers may impact the results of this meta-analysis. Third, relatively large heterogeneity was found in the majority of the analyses. Fourth, expression of these markers was detected using an IHC method, which suffers from severe limitations as no functional test, non-quantitative and non-canonical analysis. Fifth, we evaluated and calculated the HRs via survival curves, which might reduce the reliability of the results. Finally, publication bias was observed in the pooled HR for the OS and DFS of ALDH1 expression, thus potentially inflating the estimate for the association of CSCs with poor prognosis. Despite these limitations, we have provided a comprehensive analysis of the association between CSC markers and the clinicopathology and prognosis of OC patients.

\section{Conclusion}

In conclusion, our meta-analysis revealed the value of ALDH1, CD133 and CD44s as 3 significant clinical indicators for patients with OC. ALDH1 overexpression was related to FIGO stage and lymph invasion. CD133 overexpression was significantly correlated with FIGO stage and tumor differentiation grade. CD44s overexpression was associated with chemotherapy resistance. Moreover, ALDH1, CD117, CD133 and CD44s were associated with worse prognosis. Combined detection of ALDH1, CD117, CD133 and CD44s expression may be a powerful tool in clinical practice for predicting prognosis of patients with OC. However, because of certain limitations, further well-designed studies with large samples, standard cohorts, and long-term follow-up are required for confirmation.

\section{Acknowledgements}

This work was supported by grants from National Science Foundation of China (8176110049), National Science Foundation of Guangxi (2017GXNSFBA1980047), the Bureau of Public Health of Guangxi Province(Z2015624) and the Natural Science Foundation of Guangxi Medical University Programs (GXMUYSF201630). 


\section{Cellular Physiology Cell Physiol Biochem 2018;46:1716-1726

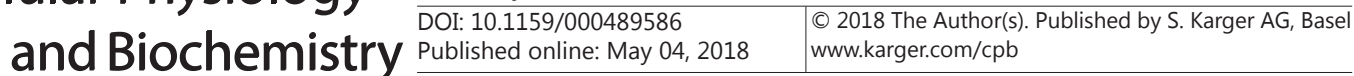 \\ Tao et al.: Ovarian Cancer Stem Cell Markers}

Yifeng Tao, Meiqin Li and conceived and designed the experiments; Min Fang, Hui Li, Dan Mo and Tian Zeng analyzed data, Yifeng Tao, Hui Li, Min Fang, Rongyong Huang and Meiqin Li wrote the manuscript. All authors reviewed and approved the manuscript.

\section{Disclosure Statement}

No conflict of interests exists.

\section{References}

1 Siegel RL, Miller KD, Jemal A: Cancer statistics, 2016 CA Cancer J Clin 2016;66:7-30.

$\checkmark 2$ Kipps E, Tan DS, Kaye SB: Meeting the challenge of ascites in ovarian cancer: New avenues for therapy and research. Nat Rev Cancer 2013;13:273-282.

-3 Wefers C, Lambert LJ, Torensma R, Hato SV: Cellular immunotherapy in ovarian cancer: Targeting the stem of recurrence. Gynecol Oncol 2015;137:335-342.

4 Wang M, Zhang Y, Wang T, Zhang J, Zhou Z, Sun Y, Wang S, Shi Y, Luan X, Zhang Y, Wang Y, Wang Y, Zou Z, Kang L, Liu H: The usp7 inhibitor p5091 induces cell death in ovarian cancers with different p53 status. Cell Physiol Biochem 2017;43:1755-1766.

5 Nguyen LV, Vanner R, Dirks P, Eaves CJ: Cancer stem cells: An evolving concept. Nat Rev Cancer 2012;12:133-143.

6 Yu W, Li L, Zheng F, Yang W, Zhao S, Tian C, Yin W, Chen Y, Guo W, Zou L, Deng W: Beta-catenin cooperates with creb binding protein to promote the growth of tumor cells. Cell Physiol Biochem 2017;44:467-478.

7 Ye H, Zheng T, Li W, Li X, Fu X, Huang Y, Hu C, Li J, Huang J, Liu Z, Zheng L, Zheng Y: Ovarian stem cell nests in reproduction and ovarian aging. Cell Physiol Biochem 2017;43:1917-1925.

-8 Curley MD, Garrett LA, Schorge JO, Foster R, Rueda BR: Evidence for cancer stem cells contributing to the pathogenesis of ovarian cancer. Front Biosci 2011;16:368-392.

-9 Lagana AS, Colonese F, Colonese E, Sofo V, Salmeri FM, Granese R, Chiofalo B, Ciancimino L, Triolo O: Cytogenetic analysis of epithelial ovarian cancer's stem cells: An overview on new diagnostic and therapeutic perspectives. Eur J Gynaecol Oncol 2015;36:495-505.

10 Ye H, Li X, Zheng T, Hu C, Pan Z, Huang J, Li J, Li W, Zheng Y: The hippo signaling pathway regulates ovarian function via the proliferation of ovarian germline stem cells. Cell Physiol Biochem y 2017;41:1051-1062.

11 Burgos-Ojeda D, Rueda BR, Buckanovich RJ: Ovarian cancer stem cell markers: Prognostic and therapeutic implications. Cancer Lett 2012;322:1-7.

12 Tayama S, Motohara T, Narantuya D, Li C, Fujimoto K, Sakaguchi I, Tashiro H, Saya H, Nagano O, Katabuchi $\mathrm{H}$ : The impact of epcam expression on response to chemotherapy and clinical outcomes in patients with epithelial ovarian cancer. Oncotarget 2017;8:44312-44325.

13 Huang R, Wu D, Yuan Y, Li X, Holm R, Trope CG, Nesland JM, Suo Z: Cd117 expression in fibroblastslike stromal cells indicates unfavorable clinical outcomes in ovarian carcinoma patients. PloS One 2014;9:e112209.

-14 Nakamura K, Terai Y, Tanabe A, Ono YJ, Hayashi M, Maeda K, Fujiwara S, Ashihara K, Nakamura M, Tanaka Y, Tanaka T, Tsunetoh S, Sasaki H, Ohmichi M: Cd24 expression is a marker for predicting clinical outcome and regulates the epithelial-mesenchymal transition in ovarian cancer via both the akt and erk pathways. Oncol Rep 2017;37:3189-3200.

15 McLean K, Gong Y, Choi Y, Deng N, Yang K, Bai S, Cabrera L, Keller E, McCauley L, Cho KR, Buckanovich RJ: Human ovarian carcinoma-associated mesenchymal stem cells regulate cancer stem cells and tumorigenesis via altered bmp production. J Clin Invest 2011;121:3206-3219.

16 Zhang S, Balch C, Chan MW, Lai HC, Matei D, Schilder JM, Yan PS, Huang TH, Nephew KP: Identification and characterization of ovarian cancer-initiating cells from primary human tumors. Cancer Res 2008;68:43114320 .

17 Cho EY, Choi Y, Chae SW, Sohn JH, Ahn GH: Immunohistochemical study of the expression of adhesion molecules in ovarian serous neoplasms. Pathol Int 2006;56:62-70. 


\section{Cellular Physiology Cell Physiol Biochem 2018;46:1716-1726 \begin{tabular}{l|l} 
and Biochemistry Published online: May 04, 2018 & $\begin{array}{l}\text { (c) } 2018 \text { The Author(s). Published by S. Karger AG, Basel } \\
\text { www.karger.com/cpb }\end{array}$ \\
\hline
\end{tabular}}

18 Zhang J, Guo X, Chang DY, Rosen DG, Mercado-Uribe I, Liu J: Cd133 expression associated with poor prognosis in ovarian cancer. Mod Pathol 2012;25:456-464.

19 Yu L, Zhu B, Wu S, Zhou L, Song W, Gong X, Wang D: Evaluation of the correlation of vasculogenic mimicry, aldh1, kiss-1, and macc1 in the prediction of metastasis and prognosis in ovarian carcinoma. Diagn Pathol 2017;12:23.

20 Brustmann H: Immunohistochemical detection of human telomerase reverse transcriptase (htert) and c-kit in serous ovarian carcinoma: A clinicopathologic study. Gynecol Oncol 2005;98:396-402.

-21 Rodriguez-Rodriguez L, Sancho-Torres I, Mesonero C, Gibbon DG, Shih WJ, Zotalis G: The cd44 receptor is a molecular predictor of survival in ovarian cancer. Med Oncol 2003;20:255-263.

22 Chang B, Liu G, Xue F, Rosen DG, Xiao L, Wang X, Liu J: Aldh1 expression correlates with favorable prognosis in ovarian cancers. Mod Pathol 2009;22:817-823.

-23 Ferrandina G, Martinelli E, Petrillo M, Prisco MG, Zannoni G, Sioletic S, Scambia G: Cd133 antigen expression in ovarian cancer. BMC Cancer 2009;9:221.

24 Elzarkaa AA, Sabaa BE, Abdelkhalik D, Mansour H, Melis M, Shaalan W, Farouk M, Malik E, Soliman AA: Clinical relevance of cd44 surface expression in advanced stage serous epithelial ovarian cancer: A prospective study. J Cancer Res Clin Oncol 2016;142:949-958.

25 Liang J, Yang B, Cao Q, Wu X: Association of vasculogenic mimicry formation and cd133 expression with poor prognosis in ovarian cancer. Gynecol Obstet Invest 2016;81:529-536.

-26 Ayub TH, Keyver-Paik MD, Debald M, Rostamzadeh B, Thiesler T, Schroder L, Barchet W, Abramian A, Kaiser C, Kristiansen G, Kuhn W, Kubler K: Accumulation of aldh1-positive cells after neoadjuvant chemotherapy predicts treatment resistance and prognosticates poor outcome in ovarian cancer. Oncotarget 2015;6:16437-16448.

-27 Tonary AM, Macdonald EA, Faught W, Senterman MK, Vanderhyden BC: Lack of expression of c-kit in ovarian cancers is associated with poor prognosis. Int J Cancer 2000;89:242-250.

-28 DerSimonian R, Laird N: Meta-analysis in clinical trials. Control Clin Trials 1986; 7:177-188.

29 Mantel N, Haenszel W: Statistical aspects of the analysis of data from retrospective studies of disease. J Natl Cancer Inst 1959;22:719-748.

30 Jing H, Liu XY, Chen YL, Bai LP, Zheng A: expression level of membrane-associated proteins numb in epithelial ovarian carcinoma and its relationship with ovarian cancer stem cell markers cd117, cd133, aldh1. Sichuan Da Xue Xue Bao Yi Xue Ban 2016;47:878-882.

-31 Ruscito I, Cacsire Castillo-Tong D, Vergote I, Ignat I, Stanske M, Vanderstichele A, Ganapathi RN, Glajzer J, Kulbe H, Trillsch F, Mustea A, Kreuzinger C, Benedetti Panici P, Gourley C, Gabra H, Kessler M, Sehouli J, Darb-Esfahani S, Braicu EI: Exploring the clonal evolution of cd133/aldehyde-dehydrogenase-1 (aldh1)positive cancer stem-like cells from primary to recurrent high-grade serous ovarian cancer (hgsoc). A study of the ovarian cancer therapy-innovative models prolong survival (octips) consortium. Eur J Cancer 2017;79:214-225.

-32 Huang R, Li X, Holm R, Trope CG, Nesland JM, Suo Z: The expression of aldehyde dehydrogenase 1 (aldh1) in ovarian carcinomas and its clinicopathological associations: A retrospective study. BMC Cancer 2015; 15:502.

-33 Sun Y, Jia X, Wu X: High expressions of lgr5 and aldh1 in primary epithelial ovarian cancer correlate with advanced tumor stage and grade as well as poor prognosis of the patients. Gynecol Obstet Invest 2015

34 Chen PX, Li QY, Yang Z: Musashi-1 expression is a prognostic factor in ovarian adenocarcinoma and correlates with aldh-1 expression. Pathol Oncol Res 2015;21:1133-1140.

-35 Liebscher CA, Prinzler J, Sinn BV, Budczies J, Denkert C, Noske A, Sehouli J, Braicu EI, Dietel M, DarbEsfahani S: Aldehyde dehydrogenase 1/epidermal growth factor receptor coexpression is characteristic of a highly aggressive, poor-prognosis subgroup of high-grade serous ovarian carcinoma. Hum Pathol 2013;44:1465-1471.

-36 Kuroda T, Hirohashi Y, Torigoe T, Yasuda K, Takahashi A, Asanuma H, Morita R, Mariya T, Asano T, Mizuuchi M, Saito T, Sato N: Aldh1-high ovarian cancer stem-like cells can be isolated from serous and clear cell adenocarcinoma cells, and aldh1 high expression is associated with poor prognosis. PloS One 2013;8:e65158.

37 Ricci F, Bernasconi S, Porcu L, Erba E, Panini N, Fruscio R, Sina F, Torri V, Broggini M, Damia G: Aldh enzymatic activity and cd133 positivity and response to chemotherapy in ovarian cancer patients. Am J Cancer Res 2013;3:221-229. 


\section{Cellular Physiology Cell Physiol Biochem 2018;46:1716-1726

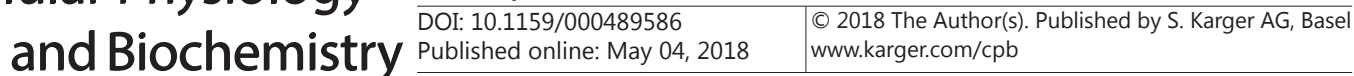

38 Wang YC, Yo YT, Lee HY, Liao YP, Chao TK, Su PH, Lai HC: Aldh1-bright epithelial ovarian cancer cells are associated with cd44 expression, drug resistance, and poor clinical outcome. Am J Pathol 2012;180:11591169.

39 Rahadiani N, Ikeda J, Mamat S, Matsuzaki S, Ueda Y, Umehara R, Tian T, Wang Y, Enomoto T, Kimura T, Aozasa K, Morii E: Expression of aldehyde dehydrogenase 1 (aldh1) in endometrioid adenocarcinoma and its clinical implications. Cancer Sci 2011;102:903-908.

-40 Deng S, Yang X, Lassus H, Liang S, Kaur S, Ye Q, Li C, Wang LP, Roby KF, Orsulic S, Connolly DC, Zhang Y, Montone K, Butzow R, Coukos G, Zhang L: Distinct expression levels and patterns of stem cell marker, aldehyde dehydrogenase isoform 1 (aldh1), in human epithelial cancers. PloS One 2010;5:e10277.

-41 Landen CN, Jr., Goodman B, Katre AA, Steg AD, Nick AM, Stone RL, Miller LD, Mejia PV, Jennings NB, Gershenson DM, Bast RC, Jr., Coleman RL, Lopez-Berestein G, Sood AK: Targeting aldehyde dehydrogenase cancer stem cells in ovarian cancer. Mole Cancer Ther 2010;9:3186-3199.

42 Kim KH, Kang YJ, Jo JO, Ock MS, Moon SH, Suh DS, Yoon MS, Park ES, Jeong N, Eo WK, Kim HY, Cha HJ: Ddx4 (dead box polypeptide 4) colocalizes with cancer stem cell marker cd133 in ovarian cancers. Biochem Biophys Res Commun 2014;447:315-322.

43 Qin Q, Sun Y, Fei M, Zhang J, Jia Y, Gu M, Xia R, Chen S, Deng A: Expression of putative stem marker nestin and cd133 in advanced serous ovarian cancer. Neoplasma 2012;59:310-315.

44 Bonneau C, Rouzier R, Geyl C, Cortez A, Castela M, Lis R, Darai E, Touboul C: Predictive markers of chemoresistance in advanced stages epithelial ovarian carcinoma. Gynecol Oncol 2015;136:112-120.

-45 Wang H, Tan M, Zhang S, Li X, Gao J, Zhang D, Hao Y, Gao S, Liu J, Lin B: Expression and significance of cd44, cd47 and c-met in ovarian clear cell carcinoma. Int J Mol Sci 2015;16:3391-3404.

46 Gao Y, Foster R, Yang X, Feng Y, Shen JK, Mankin HJ, Hornicek FJ, Amiji MM, Duan Z: Up-regulation of cd44 in the development of metastasis, recurrence and drug resistance of ovarian cancer. Oncotarget 2015;6:93139326.

-47 Zhu LC, Gao J, Hu ZH, Schwab CL, Zhuang HY, Tan MZ, Yan LM, Liu JJ, Zhang DY, Lin B: Membranous expressions of lewis y and cam-dr-related markers are independent factors of chemotherapy resistance and poor prognosis in epithelial ovarian cancer. Am J Cancer Res 2015;5:830-843.

48 Zhang J, Chang B, Liu J: Cd44 standard form expression is correlated with high-grade and advanced-stage ovarian carcinoma but not prognosis. Hum Pathol 2013;44:1882-1889.

49 Sillanpaa S, Anttila MA, Voutilainen K, Tammi RH, Tammi MI, Saarikoski SV, Kosma VM: Cd44 expression indicates favorable prognosis in epithelial ovarian cancer. Clin Cancer Res 2003;9:5318-5324.

50 Hu Z, Gao J, Zhang D, Liu Q, Yan L, Gao L, Liu J, Liu D, Zhang S, Lin B: High expression of lewis y antigen and cd44 is correlated with resistance to chemotherapy in epithelial ovarian cancers. PloS One 2013;8:e57250.

51 Ryabtseva OD, Lukianova NY, Shmurakov YA, Polishchuk LZ, Antipova SV: Significance of adhesion molecules expression for estimation of serous ovarian cancer prognosis. Exp Oncol 2013;35:211-218.

\$52 Liu M, Mor G, Cheng H, Xiang X, Hui P, Rutherford T, Yin G, Rimm DL, Holmberg J, Alvero A, Silasi DA: High frequency of putative ovarian cancer stem cells with cd44/ck19 coexpression is associated with decreased progression-free intervals in patients with recurrent epithelial ovarian cancer. Reprod Sci 2013;20:605615.

-53 Steffensen KD, Alvero AB, Yang Y, Waldstrom M, Hui P, Holmberg JC, Silasi DA, Jakobsen A, Rutherford T, Mor G: Prevalence of epithelial ovarian cancer stem cells correlates with recurrence in early-stage ovarian cancer. J Oncol 2011;2011:620523.

-54 Chen H, Hao J, Wang L, Li Y: Coexpression of invasive markers (upa, cd44) and multiple drug-resistance proteins (mdr1, mrp2) is correlated with epithelial ovarian cancer progression. Br J Cancer 2009;101:432440.

55 Ross JS, Sheehan CE, Williams SS, Malfetano JH, Szyfelbein WM, Kallakury BV: Decreased cd44 standard form expression correlates with prognostic variables in ovarian carcinomas. Am J Clin Pathol 2001;116:122-128.

56 Kayastha S, Freedman AN, Piver MS, Mukkamalla J, Romero-Guittierez M, Werness BA: Expression of the hyaluronan receptor, cd44s, in epithelial ovarian cancer is an independent predictor of survival. Clin Cancer Res 1999;5:1073-1076.

57 Shi J, Zhou Z, Di W, Li N: Correlation of cd44v6 expression with ovarian cancer progression and recurrence. BMC Cancer 2013;13:182. 


\section{Cellular Physiology Cell Physiol Biochem 2018;46:1716-1726 \begin{tabular}{l|l} 
and Biochemistry Published online: May 04, 2018 & $\begin{array}{l}\text { (c) } 2018 \text { The Author(s). Published by S. Karger AG, Basel } \\
\text { www.karger.com/cpb }\end{array}$ \\
\hline
\end{tabular}

-58 Tjhay F, Motohara T, Tayama S, Narantuya D, Fujimoto K, Guo J, Sakaguchi I, Honda R, Tashiro H, Katabuchi $\mathrm{H}$ : Cd44 variant 6 is correlated with peritoneal dissemination and poor prognosis in patients with advanced epithelial ovarian cancer. Cancer Sci 2015;106:1421-1428.

59 Hong SC, Song JY, Lee JK, Lee NW, Kim SH, Yeom BW, Lee KW: Significance of cd44v6 expression in gynecologic malignancies. J Obstet Gynaecol Res 2006;32:379-386.

-60 Gun BD, Bahadir B, Bektas S, Barut F, Yurdakan G, Kandemir NO, Ozdamar SO: Clinicopathological significance of fascin and cd44v6 expression in endometrioid carcinoma. Diagn Pathol 2012;7:80.

61 Motohara T, Fujimoto K, Tayama S, Narantuya D, Sakaguchi I, Tashiro H, Katabuchi H: Cd44 variant 6 as a predictive biomarker for distant metastasis in patients with epithelial ovarian cancer. Obstet Gynecol 2016;127:1003-1011.

62 Zhou DX, Liu YX, Xue YH: Expression of cd44v6 and its association with prognosis in epithelial ovarian carcinomas. Patholog Res Int 2012;2012:908206.

63 Yorishima T, Nagai N, Ohama K: Expression of cd44 alternative splicing variants in primary and lymph node metastatic lesions of gynecological cancer. Hiroshima J Med Sci 1997;46:21-29.

64 Darai E, Walker-Combrouze F, Fauconnier A, Madelenat P, Potet F, Scoazec JY: Analysis of cd44 expression in serous and mucinous borderline tumours of the ovary: Comparison with cystadenomas and overt carcinomas. Histopathology 1998;32:151-159.

65 Yang L, Hou J, Duang A, Sun Z: The expression and significance of cd133and nestin as the tumor stem cell markers in ovarian cancer. Linchuang He Shi Yan Yi Xue Za Zhi 2015;14:301-304.

66 Wang A, Lu L, Wang Y, Sun Y, Zhang Y, Guo C, Gu Y, Liu A: expression and clinicopathologic significance of cd44v6/cd24 in ovarian serous carcinomas. Zhonghua Bing Li Xue Za Zhi 2014;43:20-24.

67 Conic I, Stanojevic Z, Jankovic Velickovic L, Stojnev S, Ristic Petrovic A, Krstic M, Stanojevic M, Bogdanovic D, Stefanovic V: Epithelial ovarian cancer with cd117 phenotype is highly aggressive and resistant to chemotherapy. J Obstet Gynaecol Res 2015;41:1630-1637.

-68 Lassus H, Sihto H, Leminen A, Nordling S, Joensuu H, Nupponen NN, Butzow R: Genetic alterations and protein expression of kit and pdgfra in serous ovarian carcinoma. Br J Cancer 2004;91:2048-2055.

69 Khalifeh I, Munkarah AR, Schimp V, Morris R, Lawrence WD, Ali-Fehmi R: The impact of c-kit and ki-67 expression on patients prognosis in advanced ovarian serous carcinoma. Int J Gynecol Pathol 2005;24:228234.

70 Shah MM, Landen CN: Ovarian cancer stem cells: Are they real and why are they important? Gynecol Oncol 2014;132:483-489.

71 Foster R, Buckanovich RJ, Rueda BR: Ovarian cancer stem cells: Working towards the root of stemness. Cancer Lett 2013;338:147-157.

72 Tomita H, Tanaka K, Tanaka T, Hara A: Aldehyde dehydrogenase 1a1 in stem cells and cancer. Oncotarget 2016;7:11018-11032.

73 Chanda B, Ditadi A, Iscove NN, Keller G: Retinoic acid signaling is essential for embryonic hematopoietic stem cell development. Cell 2013;155:215-227.

74 Ronnstrand L: Signal transduction via the stem cell factor receptor/c-kit. Cell Mol Life Sci;61:2535-2548.

75 Besmer P, Murphy JE, George PC, Qiu FH, Bergold PJ, Lederman L, Snyder HW, Jr., Brodeur D, Zuckerman EE, Hardy WD: A new acute transforming feline retrovirus and relationship of its oncogene v-kit with the protein kinase gene family. Nature 1986;320:415-421.

-76 Bauer N, Fonseca AV, Florek M, Freund D, Jaszai J, Bornhauser M, Fargeas CA, Corbeil D: New insights into the cell biology of hematopoietic progenitors by studying prominin-1 (cd133). Cells Tissues Organs 2008;188:127-138.

77 Yan Y, Zuo X, Wei D: Concise review: Emerging role of cd44 in cancer stem cells: A promising biomarker and therapeutic target. Stem Cells Transl Med 2015;4:1033-1043.

78 Bourguignon LY, Peyrollier K, Xia W, Gilad E: Hyaluronan-cd44 interaction activates stem cell marker nanog, stat-3-mediated mdr1 gene expression, and ankyrin-regulated multidrug efflux in breast and ovarian tumor cells. J Biol Chem 2008;283:17635-17651. 